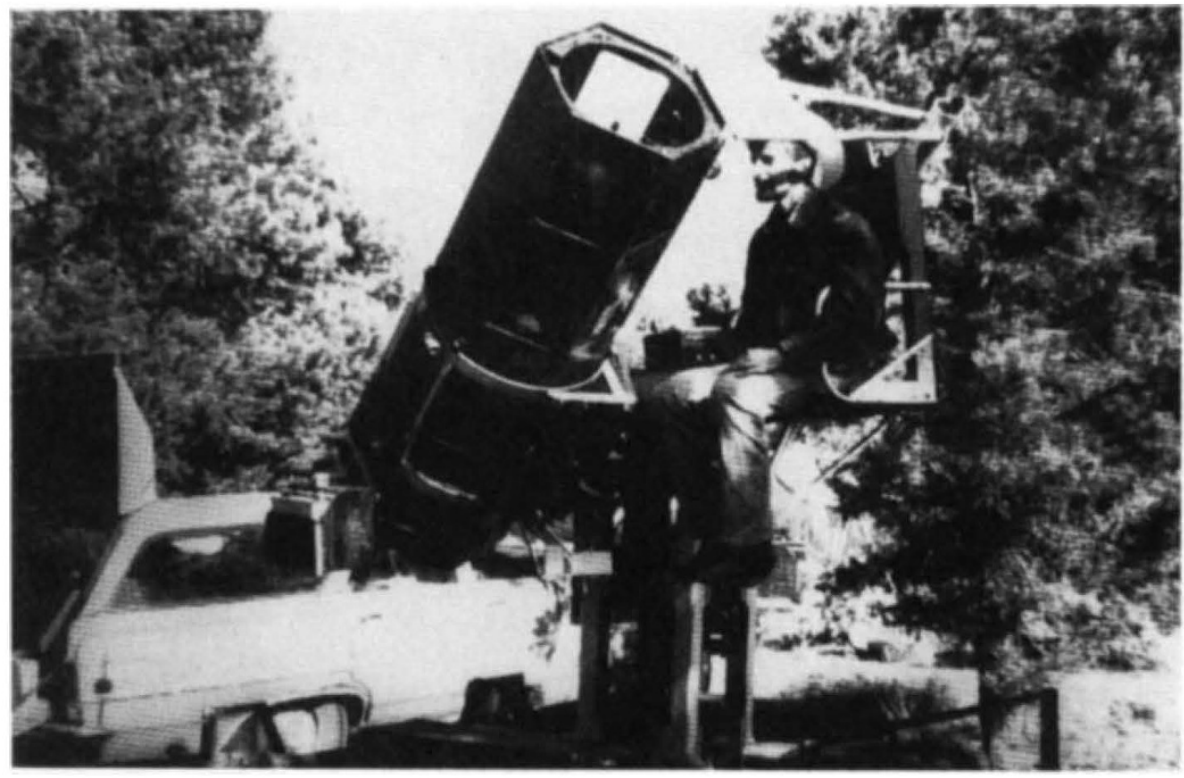

Riding high - sometimes it is easier to attach one's self to the end of one's telescope than to follow the eyepiece round. Pictured here is Pierre Schwaar's merry-go-round telescope.

made from such bits and pieces as a Meccano set, a fishing reel and even a water clock. Heath Robinson would have enjoyed this chapter.

Another intriguing problem is whether the eyepiece should move or be stationary. When looking up at the immense columns of masonry that support the vast tube of the 1.83-metre (72-inch) telescope built by William Parsons, the Third Earl of Rosse, at Birr Castle, Parsontown, in the mid-nineteenth century, I have sometimes tried to imagine what it was like on a windy night to follow in the dark the moving eyepiece at its newtonian focus. I was pleased to find that Manly uses this great telescope, the Leviathan, to illustrate the difficulties of a moving eyepiece: by any standards it was blatantly odd. He might well have also mentioned the observer's cage at the prime focus of the 200 -inch telescope at Mount Palomar - by modern standards that is certainly odd. How to provide a moving telescope with a stationary eyepiece is a classical problem that has been tackled in many ways. Manly tells us about some of the solutions, among them the Springfield mount, which is basically a newtonian telescope mounted at the eyepiece end.

Although this book is a collection of oddities, it is not just a rag-bag. Manly tries to fit his examples into a coherent framework structured around the problems of designing telescopes and makes copious references to articles giving more information. To my mind, he would have done better to restrict his coverage to optical telescopes instead of including instruments designed for radio, infrared and cosmic rays. For example, he does not do justice to the oddities and problems in designing radiotelescopes that would need a book in itself

Many astronomers, in fact many scien- tists, are insufficiently aware that it is the progress of instrument design that spearheads the progress of their science. Too many of them do not know how their instruments are made or what is inside the black boxes that they use; it would do them good to read a book like this.

R. Hanbury Brown, emeritus professor of physics at the University of Sydney, is at the White Cottage, Penton Mewsey, Andover,

\section{Science and the underdog}

John W. Galloway

Cancer Selection: The New Theory of Evolution. By James Graham. Aculeus, PO Box 142, Lexington, Virginia 24450 , USA: 1992. Pp. 213. $\$ 20$.

WE have a good idea of the sorts of molecular events that underlie the initiation and growth of cancers. They all involve damage to a narrow spectrum of a few dozen genes (or the neutralization of the proteins for which they code). And all these genes concern the regulation of DNA replication and cell division, or differentiation.

Do we have a comparable picture of the molecular basis of evolution? James Graham thinks we do. He believes it is this self-same set of genes. Mr Graham, an avowed amateur scientist, has a bone think that the theory of evolution in itself explains the appearance of complex organisms such as people, although it is $\mathrm{OK}$ for simple things such as plants and colonial animals. I think I agree with him. Evolution 'by natural selection' Hampshire SP11 ORQ, UK. to pick with evolutionists. He does not does not explicitly seem to explain complexity (notwithstanding the eloquence of people such as Richard Dawkins). Plenty of simple things are extremely successful. Graham suggests that complexity can be roughly measured by the size of an organism and the number of different cell types it contains. And, because many cancers probably result from the failure of proliferation and differentiation mechanisms, he is able to argue, as he already has in the Journal of Theoretical Biology, that cancer might drive such mechanisms to being more varied - and organisms to becoming more complex.

That cancer is the result of perturbations in the molecular mechanisms underlying development presumably goes without saying. The idea that any cell embarking on a cancerous path is part of an evolutionary experiment seems self-evident; the suggestion that much diversity (within the immune system for example) is the result of the evolutionary pressure of infections and other diseases in the past can hardly be argued with.

Finally, it seems fairly well established that, for animal cells, differentiation and cell division act against one another, with cancer as a 'tug of war' between the two processes. Graham would thus have us believe that diversification of differentiation mechanisms is the result of a defensive response to uncontrolled cell division. I, at least, like the idea.

Unfortunately, Graham spoils his good idea by his advocacy of it. He is simply too self-indulgent, nowhere more obviously than in his attacks on those who have not accepted his theory and those who he thinks would not have accepted it, had they had a chance. These include a variety of well-known evolutionists of all possible stripes Darwin, Stephen Jay Gould, Lysenko, Marx. (Indeed, he seems to have detected a marxist conspiracy on the loose, trying to suppress his ideas.) Calling them all crackpots and questioning their integrity can be a bit wearisome unless it is done with imagination.

Graham's abuse of scientists tells us little about them but much about him; it is the language of the underdog. Indeed, my advice to him would be to stop writing for a bit and start reading (how about Gould's Wonderful Life?) - and, of course, to become more philosophical. I am a great believer in everyone, not just the professionals, joining the crew of the good ship Science. But that does not give Graham an automatic right for his ideas to be enthusiastically piped aboard.

John W. Galloway is at the Nuffield Foundation, 28 Bedford Square, London WC1B 3EG, UK. 